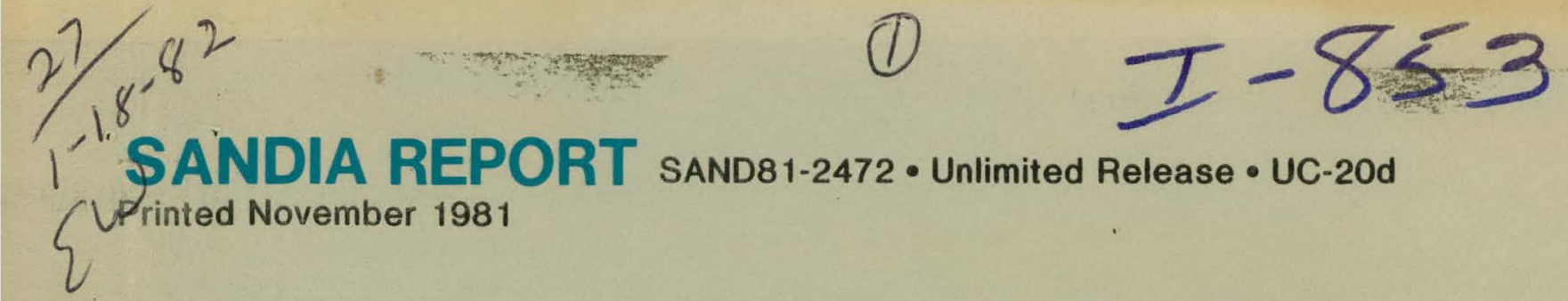

\title{
Radiation-Induced Tensile Stresses in Fission-Blanket Components
}

Marlin E. Kipp

\author{
Prepared by \\ Sandia National Laboratories \\ Albuquerque, New Mexico 87185 and Livermore, California 94550 \\ for the United States Department of Energy \\ under Contract DE-AC04-76DP00789
}

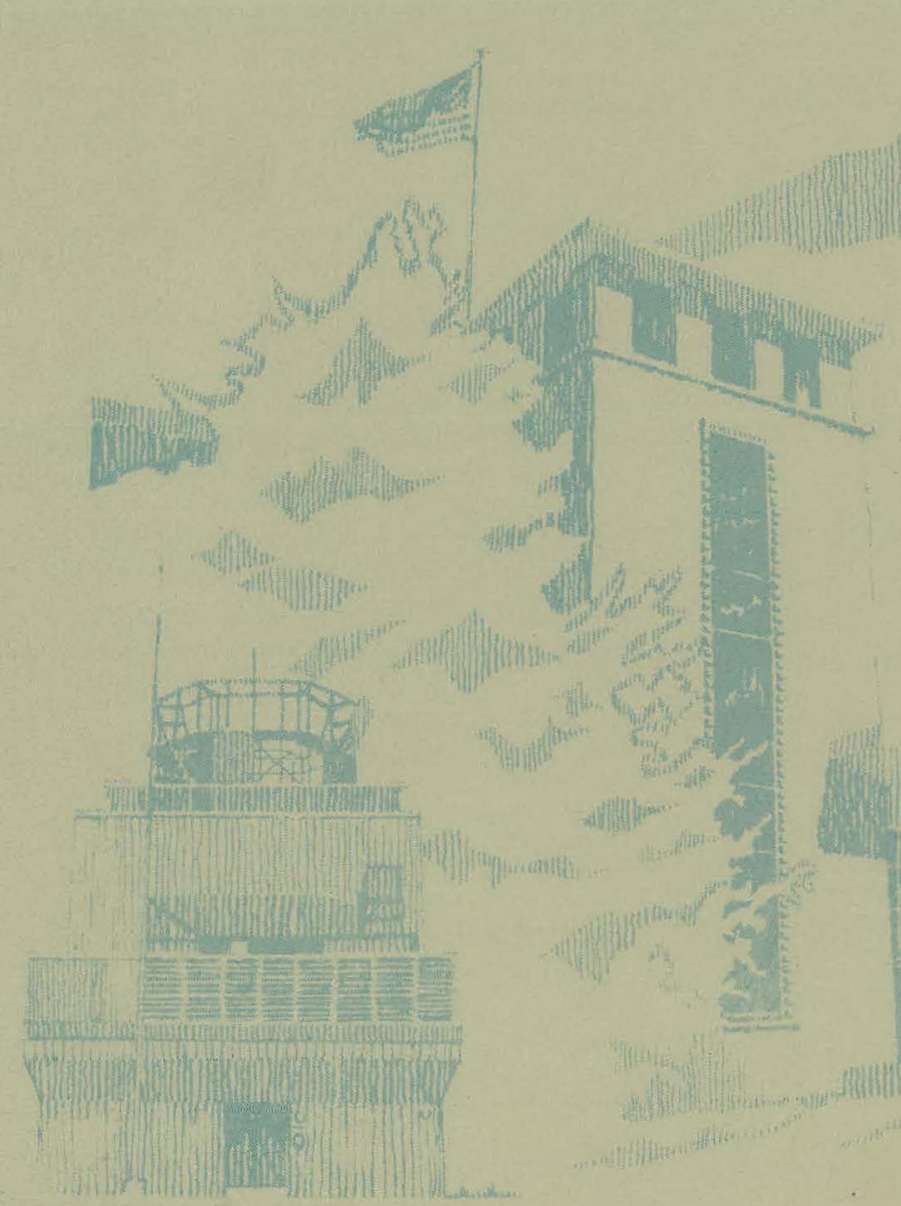




\section{DISCLAIMER}

This report was prepared as an account of work sponsored by an agency of the United States Government. Neither the United States Government nor any agency Thereof, nor any of their employees, makes any warranty, express or implied, or assumes any legal liability or responsibility for the accuracy, completeness, or usefulness of any information, apparatus, product, or process disclosed, or represents that its use would not infringe privately owned rights. Reference herein to any specific commercial product, process, or service by trade name, trademark, manufacturer, or otherwise does not necessarily constitute or imply its endorsement, recommendation, or favoring by the United States Government or any agency thereof. The views and opinions of authors expressed herein do not necessarily state or reflect those of the United States Government or any agency thereof. 


\section{DISCLAIMER}

Portions of this document may be illegible in electronic image products. Images are produced from the best available original document. 
Issued by Sandia National Laboratories, operated for the United States Department of Energy by Sandia Corporation.

NOTICE: This report was prepared as an account of work sponsored by an agency of the United States Government. Neither the United States Government nor any agency thereof, nor any of their employees, nor any of their contractors, subcontractors, or their employees, makes any warranty, express or implied, or assumes any legal liability or responsibility for the accuracy, or implied, or assumes any legal liability or responsibility for the accuracy, completeness, or usefulness of any information, apparatus, product, or prorights. Reference herein to any specific commercial product, process, or service by trade name, trademark, manufacturer, or otherwise, does not necessarily constitute or imply its endorsement, recommendation, or favoring by the United States Government, any agency thereof or any of their contractors or subcontractors. The views and opinions expressed herein do not necessarily state or reflect those of the United States Government, any agency thereof or any of their contractors or subcontractors.

Printed in the United States of America Available from

National Technical Information Service U.S. Department of Commerce

5285 Port Royal Road

Springfield, VA 22161

NTIS price codes

Printed copy: $\$ 6.00$

Microfiche copy: A01 
S.AN

Unlimited Release

Printed November 1981

\title{
Radiation-Induced Tensile Stresses in Fission- Blanket Components
}

\author{
M. E. Kipp \\ Computational Physics \& Mechanics Division 5531 \\ Sandia National Laboratories \\ Albuquerque, New Mexico 87185
}

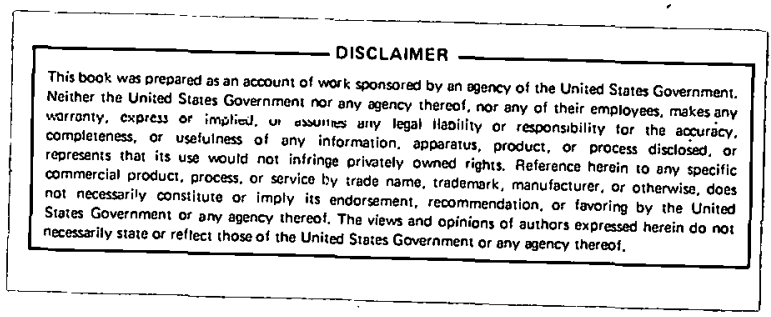

\begin{abstract}
A particle-beam fusion-fission hybrid reactor includes a surrounding blanket for energy production and for breeding fissile fuel. The blanket is subjected to radiation deposition pulses at the operating frequency of the fusion driver. A circulating coolant will remove heat from the blanket region. Onedimensional studies were made to examine possible configurations for the blanket elements. Depleted uranium solid plates, cylinders, and spheres were the initial choices. Uniform radiation deposition was assumed across the geometry, with the particular concern being the level of tension induced by the deposition pulses. The high tensions that appear in the solid cylindrical and spherical cases could be mitigated by the presence of hollow cores.
\end{abstract}




\section{Contents}

Page

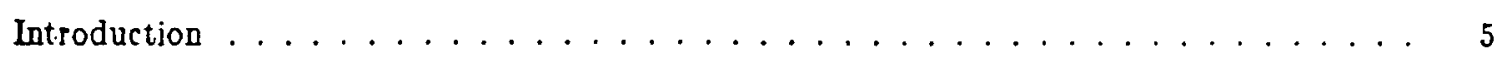

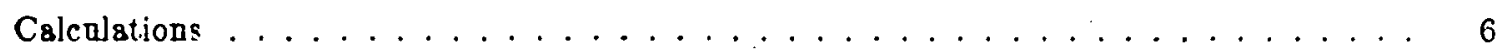

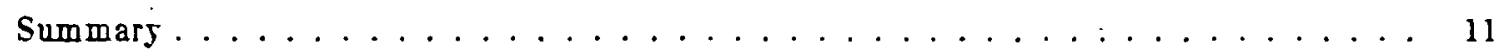

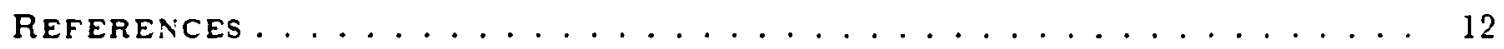

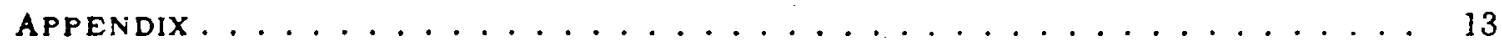




\section{Introduction}

In the particle beam fusion-fission hybrid reactor; a surrounding blanket is subjected to radiation pulses at the operating frequency of the fusion driver. The blanket generates additional energy and neutron multiplication from fission reactions within the blanket elements [1]. Radiation-induced shock waves are expected to arise within the fuel elements of the blanket, with the interaction of these waves causing the formation of tensile stresses.

As part of the scoping studies for the blanket design, an eraluation of the tensile stresses was appropriate [2]. Within the study reported here, basic geometric configurations were considered for a single structural material-depleted uranjum. The geometries consisted of plates, cylinders, and spheres, forms out of which the internal cooling structure of the blanket. could be built. In addition to the variations in geometry, the influence of radiation deposition time was also considered.

The analysis of these variables, discussed in the nest section, was performed with the one-dimensional wave propagation code WONDY [3]. 


\section{Calculations}

In order to assess the influence of radiation deposition on various geometric forms in the blanket. design, it is necessary to have the radiation deposition profle, duration of deposition, and material properties.

Within the blanket, a characteristic deposition profle is shown in Figure 1 [4]. The peak energr in the depleted uranium is located nearest the radiation source, and has an amplitude of about $200 \mathrm{MJ} / \mathrm{m}^{3}$. Gradients in the deposition profle are greatest at the peak, which in this case is about $1000 \mathrm{MJ} / \mathrm{m}^{3} / \mathrm{m}$. The deposition time is expected to be accomplished within 10 to $100 \mathrm{~ns}$. The artual details of the shape and deposition time of the profle are not known at this time.

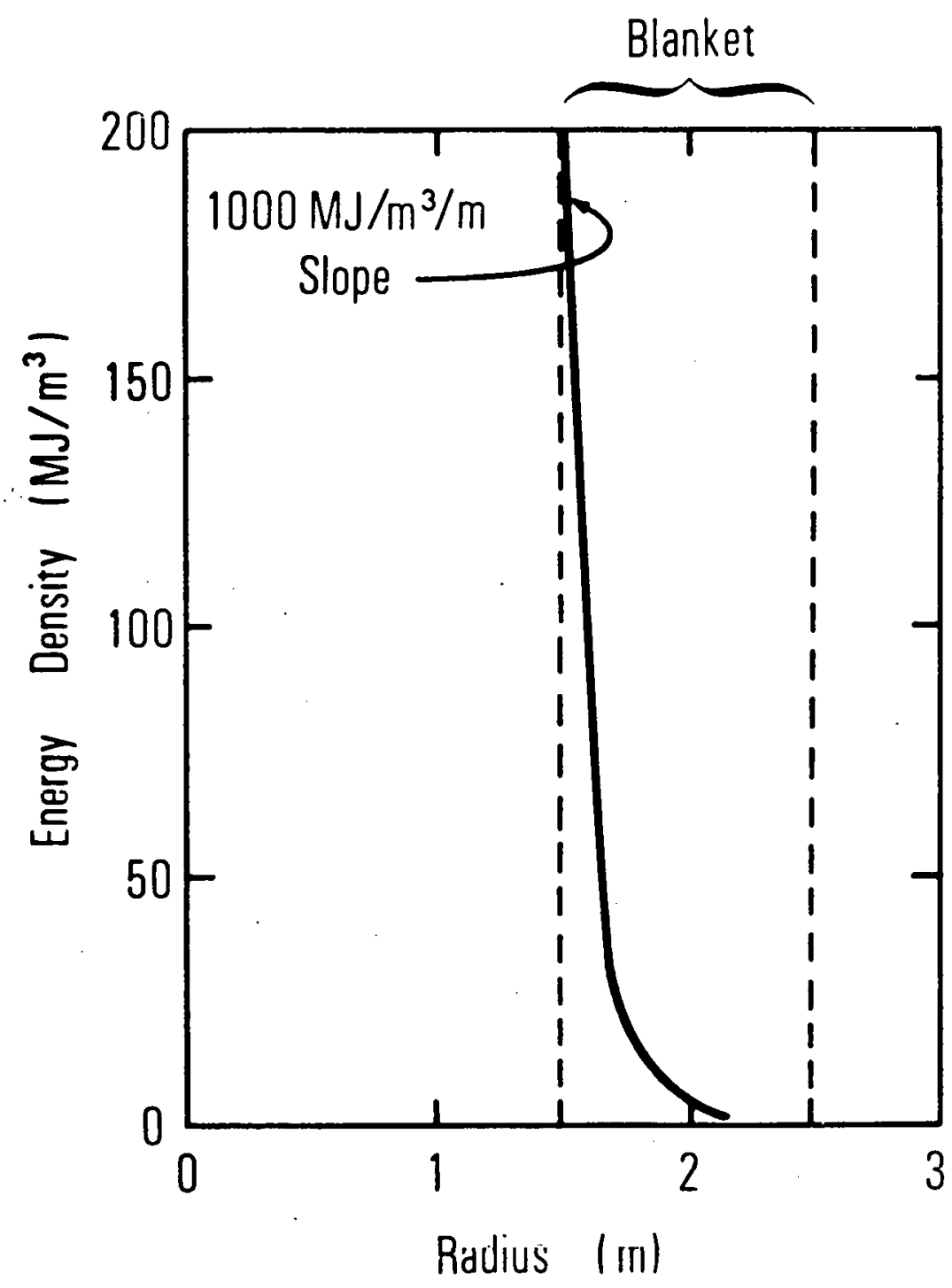

Figure 1. Approximate radiation deposition proflle in the blanket. 
The coupling of the radiation energy deposition into the depleted uranium blanket material is modeled in the code by assuming an equation of state of the material in the form [3]

$$
p=f(\rho, \varepsilon)
$$

Where $p$ is the pressure, $\rho$ is the material mass density, and $\mathcal{E}$ is the internal energy present. Impact loading causes an initial change primarily in the density of a material, thereby resulting in a pressure change. In the present case, the rapid deposition of energy into the material causes a corresponding pressure change through the relationship defined by Equation 1. The particular form of the constitutive model that is used in the code is the Mie-Gruneisen, written as

$$
p-p_{H}=\Gamma \rho\left(\varepsilon-\varepsilon_{H}\right)
$$

where $p_{H}$ and $\varepsilon_{H}$ are the Bugoniot pressure and energy, and $\Gamma$ is the Gruneisen ratio. It is this Gruneisen ratio which provides the direct coupling of energy from the radiation deposition into pressure waves in the solid.

The material properties of depleted uranium appropriate to the calculations at hand are listed in Table 1. Elastic properties were assumed to be suffcient, based upon the amplitude of compression expected from the level of deposited energy.

$\begin{array}{lll}\text { Initial density, } \rho_{0} & 18.95 \mathrm{Mg} / \mathrm{m}^{3} & {[5]} \\ \text { Initial sound velocity, } c & 2.487 \mathrm{~km} / \mathrm{s} & {[5]} \\ \text { Slope of } U_{\mathrm{a}}=U_{p}, \delta & 2.2 & {[5]} \\ \text { Poisson ratio, } \nu & 0.27 & {[6]} \\ \text { Gruneisen ratio, } \Gamma & 1.56 & {[5]} \\ & 2.0 & {[6]} \\ \text { Spall stress } & 2.4 \mathrm{GPa} & {[7]}\end{array}$

Table 1. Depleted Uranium Material Properties

Since the Gruneisen ratio directly influcnces the lercl of energy coupling, the largest value from the table has been utilized. This ensures that the induced pressures will be a worst case in terms of the tensile stresses that are subsequently generated. It should also be noted that although a spall, or fracture, stress is given, no fractures were permitted to occur, in order to assess the maximum level of tensile stresses that were induced.

The characteristic length of the geometries under consideration was taken to be $2 \mathrm{~cm}$. Referring to Figure 1, the rate of decay of the deposition profle is such that in $2 \mathrm{~cm}$, the radiation deposition would decrease from a peak of $200 \mathrm{MJ} / \mathrm{m}^{3}$ to $180 \mathrm{MJ} / \mathrm{m}^{3}$. For the present studies, $200 \mathrm{MJ} / \mathrm{m}^{3}$ was assumed to be deposited uniformly over the cross-section of the configuration.

Consider flrst the effects of major geometry types on the level of induced tensile stresses. The three one-dimensional forms evaluated were solid plates, cylinders, and spheres. Figure 2 contains the details of the geometry, ineluding the zoning used in WONDY, and the boundary conditions. Note that by sssuming a symmetry boundary on the left, only half of the problem needs to be computed. For these three cases, two deposition times were considered-10 ns and $100 \mathrm{~ns}$.

The radiation deposition time (10-100 ns) in these cases is short compared to the wave transit time across the thickness of the conflguration $(4 \mu \mathrm{s})$, so a flat pressure profile forms, with a release wave propagating away from the free surface. The amplitude of the compressive wave builds to a level of 0.31 $\mathrm{GPa}$ at the end of the deposition time. In the plate case, the release wave pulls the material into tension at the symmetry plane. Minor perturbations in the release wave formed during the deposition result in tensions slightly larger than the amplitude of the original compressive wave. If no fracture occurs at that time, the tensile wave will propagate towards the free surface unaltered in magnitude. In the cylindrical 


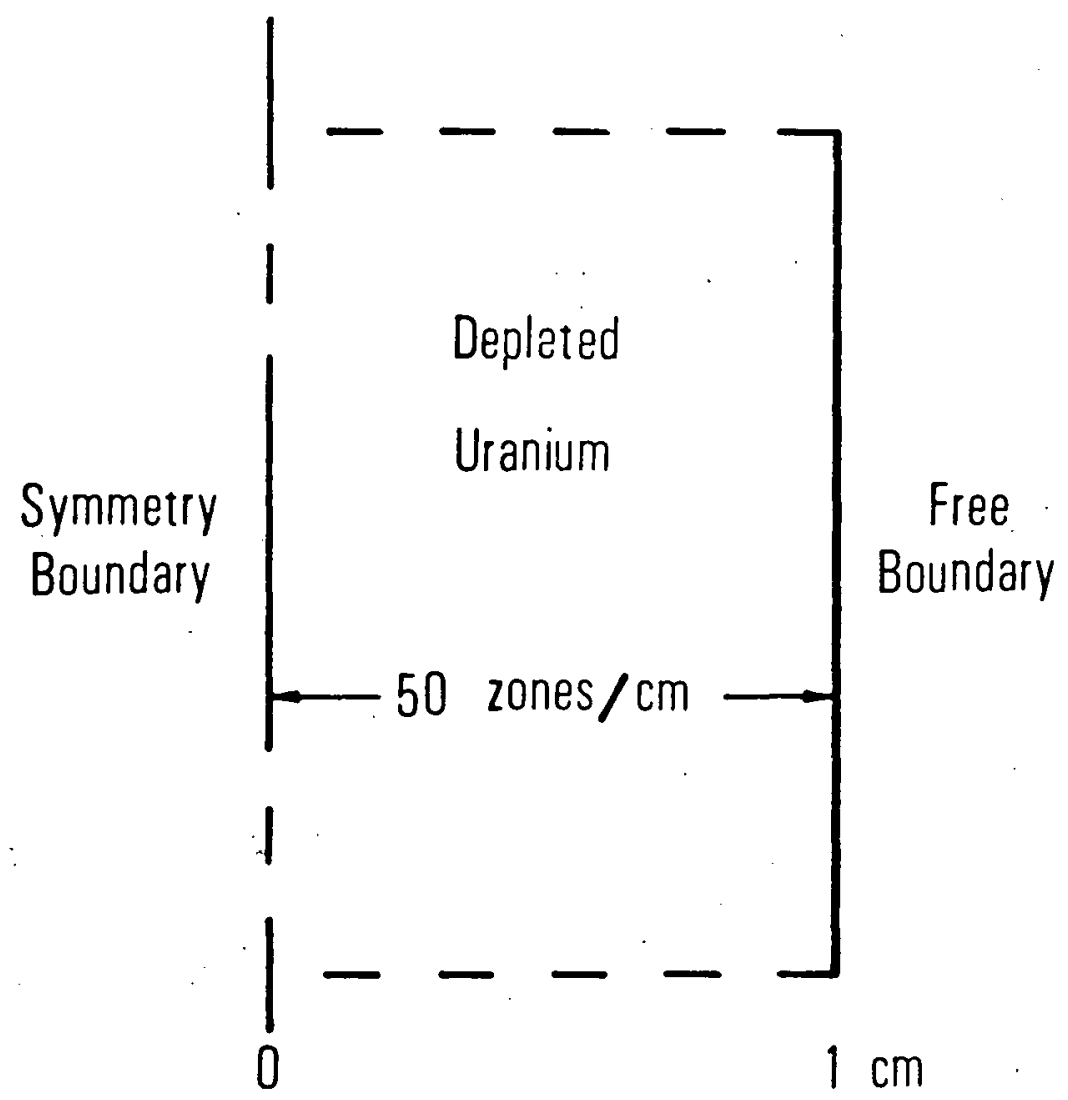

Figure 2. Initial and boundary conditions for WONDY.

and spherical geometries, the propagation is more complex because of the associated divergence, with the magnitude of the tension being considerably amplifled by the convergence of the waves onto the axis of the cylinder, or the center of the sphere. The distribution of the maximum computed tension experienced in each of these cases is plotted in Figure 3. (The development of the tension in each of these cases is show $n$ in the Appendix.)

The tension experienced by the plate is observed to be nearly uniform across its thickness, whereas the tensions generated in the cylinder and sphere are substantially larger at the center than at the surface. These estremes in tensile amplitude are limited to a very narrow region, however. The magnitudes of the resulting maximum tensions in each case are summarized in Table 2, for both deposition times.

$\begin{array}{ccc}\begin{array}{c}\text { Geometry } \\ \text { Type }\end{array} & \begin{array}{c}\text { Tensile Stress (GPa) } \\ \text { (10 ns dep. time) }\end{array} & \begin{array}{c}\text { Tensile Stress (GPa) } \\ \text { (100 ns dep. time) }\end{array} \\ 2 \text { cm Plate } & 0.40 & 0.39 \\ 2 \text { cm Cylinder } & 1.92 & 1.88 \\ 2 \text { cm Sphere } & 5.06 & 4.87\end{array}$

Toble 2. Masimum computed tensile stresses. (50 20nes $/ \mathrm{cm}$ ) 


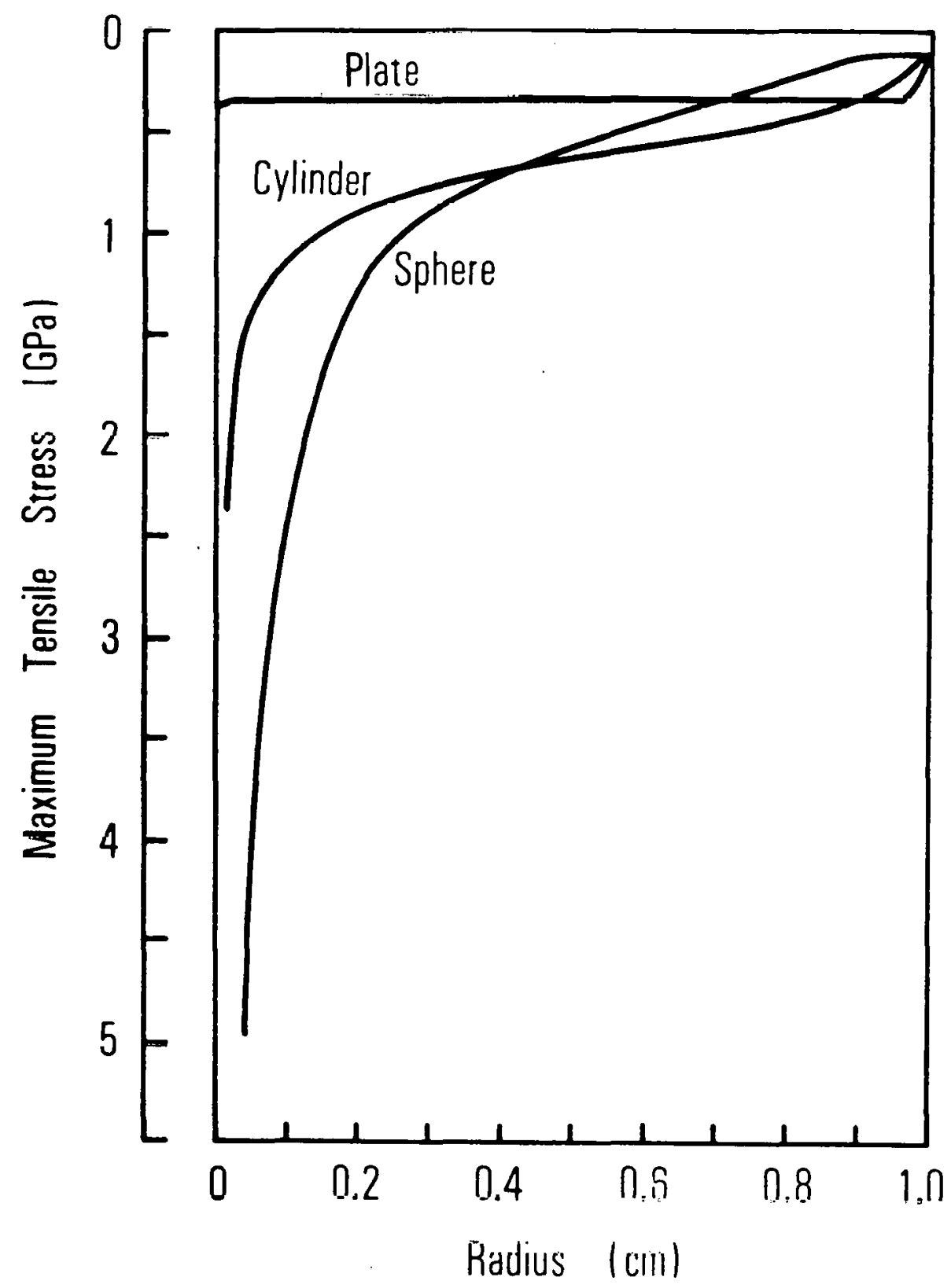

Fiqure 3. Distribution of maximum tension in the solid plate, cylinder, and sphere. (10 ns deposition time, 50 zones/cm)

Based on the spall stress given in Table 1 for depleted uranium, the solid sphere would be subjected to very localized fracture in its central region, and the plate and the cylinder would survive without fracturing. Since the influence of the change in deposition time is minor, it will not be considered further in this study. The remaining calculations that are discussed use a deposition time of $10 \mathrm{~ns}$.

The usual computational approach to dealing with narrow spikes, such as the ones observed here in the cylindrical and spherical cases, is to increase the resolution of the calculation. When the number of 
computational zones is increased by a factor of two, to 100 zones $/ \mathrm{cm}$, the masimum calculated tensions again occur at the symmetry axis. The magnitudes are recorded in Table 3.

$\begin{array}{lcc}\begin{array}{c}\text { Geometry } \\ \text { Type }\end{array} & \begin{array}{c}\text { Tensile Stress }(\mathrm{GPa}) \\ 50 \text { zones } / \mathrm{cm}\end{array} & \begin{array}{c}\text { Tensile Stress }(\mathrm{GPa}) \\ \mathbf{1 0 0} \text { zones } / \mathrm{cm}\end{array} \\ & & \\ 2 \mathrm{~cm} \text { Plate } & 0.40 & 0.39 \\ 2 \mathrm{~cm} \text { Cylinder } & 1.92 & 2.41 \\ 2 \mathrm{~cm} \text { Sphere } & 5.06 & 7.12\end{array}$

Table 3. Masimum computed tensile stresses for 50 and 100 zones $/ \mathrm{cm}$.

Although the refinement in zone size results in 8 minor change in the computed tension for the plate case, a large increase in the computed value of the masimum tensile stress is observed in the cylindrical and spherical cases. The difficulty in accurate numerical assessment of the stresses in cylindrical and spherical geometries near their respective centers lies in a stress singularity in the radius [8]. This singularity poses severe numerical problems when evaluation is attempted by the discretization techniques employed in the wavecode used in this analysis. The unrealistically large tensions that are predicted by this singularity as the radius goes to zero cannot be maintained physically, and will be reduced by localized yielding and/or fracture.

For larger diameter cylinders (and spheres), at the same deposition levels, the distribution of tension show $\mathrm{n}$ in Figure 3 , for elastic materials, scales linearly with the radius. There will then be correspondingly larger regions in which yielding or fracture will occur.

Tensile stresses in the cylinder (sphere) can be mitigated by the presence of an axial (central) hole, so that, in effect, the most severe region of convergence has been eliminated. Table 4 summarizes the changes in maximum tensile stresses observed in hollow cylinders for a variety of hole sizes with a fixed outer diameter of $2 \mathrm{~cm}$.

$\begin{array}{cc}\text { Hole Diameter } & \text { Tensile Stress (GPa) } \\ & \\ 0.1 \mathrm{~cm} & 0.82 \\ 0.2 \mathrm{~cm} & 0.72 \\ 0.5 \mathrm{~cm} & 0.63 \\ 1.0 \mathrm{~cm} & 0.47\end{array}$

Table 4. Maximum tensile stresses in hollow cylinders with outside diameter of $2 \mathrm{~cm} .(100$ zones $/ \mathrm{cm})$

The effect of enlarging the hole diameter is to dramatically decrease the tensile stress, with the maximum value approaching that of a plate (Table 1 ). 


\section{Summary}

The scoping calculations reported here provide insight into the problem of tensile stresses induced by radiation deposition in the blanket surrounding the energy source in a particle beam fusion-fission hybrid reactor. Although the flne details of the radiation deposition profle are not known, the peak clearly occurs at the position nearest the source. If the blanket components can resist fracture at the level of tensions induced there, then components further away will also be well within safe ranges of tensions. Solid spheres and cylinders appear to have very localized high levels of tension. The hollow cylinder bas levels of tension that are below the spall strength of depleted uranium, levels approaching that of the plate as the cylindrical wall thickness decreases.

This study does not address the problem of repeated tensile loading, where fatigue may contribute to the eventual appearance of fractures. The very presence of such fractures may well provide a means of mitigating further tensile stresses, and contribute to an overall stable conflguration, particularly in the solid cylindrical or spherical geometries. 


\section{REFERENCES}

1. Memorandum to Don Cook, 4251, from James Bryson and Jeff Philbin, 4452, dated May 26, 1981.

2. Memorandum to Don Cook, 4253, Prom Jeff Philbin, 4452, dated January 20, 1981.

3. R. J. Lamrence and D. S. Mason, WONDY N-A Computer Program for One-Dimensional Ware Propagation with Rezoning", Sandia Laboratories Report SC-RR-71 0284, 1971.

4. Private Communication, J. Bryson and J. Philbin, 1981.

5. "Selected Bugoniots", Los Alamos Scientific L8boratory Report. LA-4167-MS, 1969.

6. B. J. Kohn, "Compilatiou of Bugoniot Equations of State", Air Force Weapons Laboratory Report AFWL-TR-69-38, 1969.

7. S. Cochran, "Spall Studies in Uranium", Journol of Applied Physics, Vol. 48, No. 7, July 1977.

8. J. D. Achenbach, Wave Propagation in Elastic Solids, North-Holland, 1973. 


\section{APPENDIX}

This appendix contains selected plots depicting the derelopment of the tensile stress induced by the process of radiation deposition. The three one-dimensional cases shown are the solid plate, cylinder. and sphere, where the appropriate initial and boundary conditions are contained in Figure 2 of the main body of the report. Deposition time in each case is 10 ns. (Plot times are in microseconds.) 


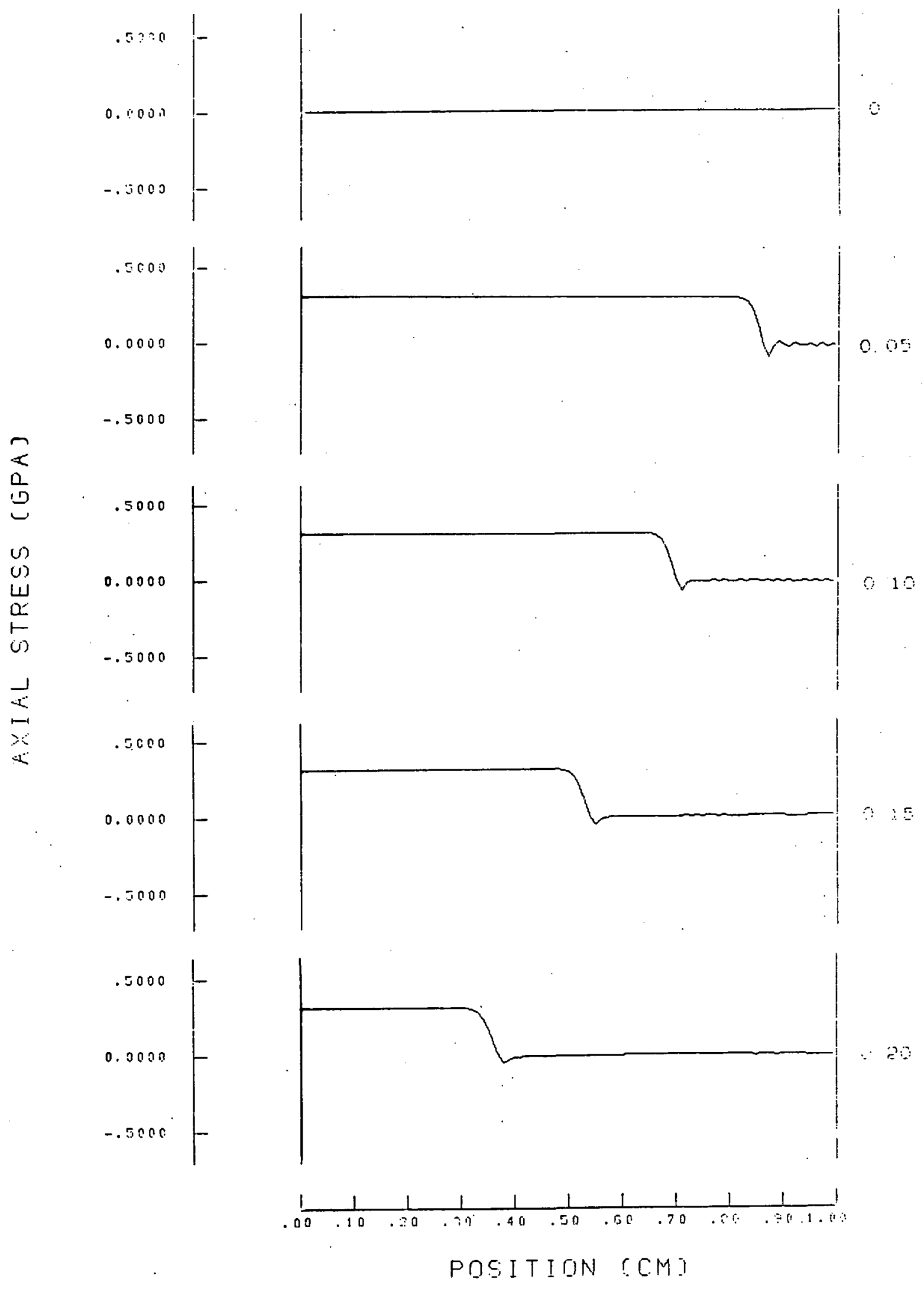



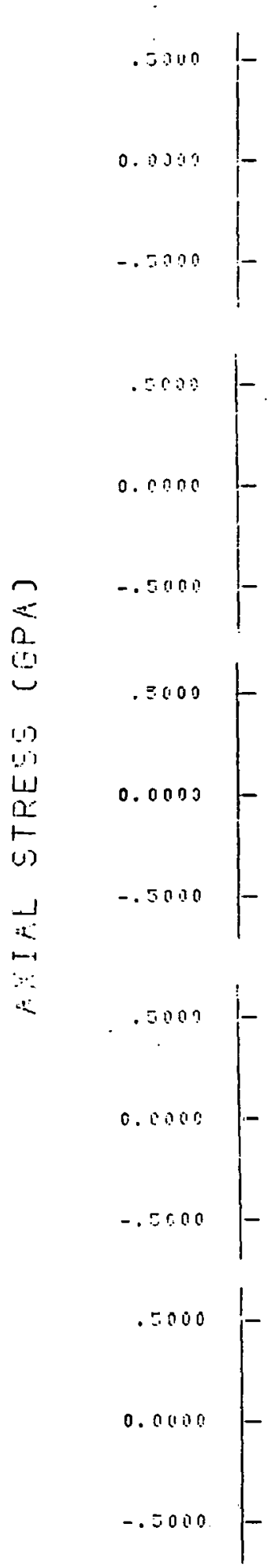

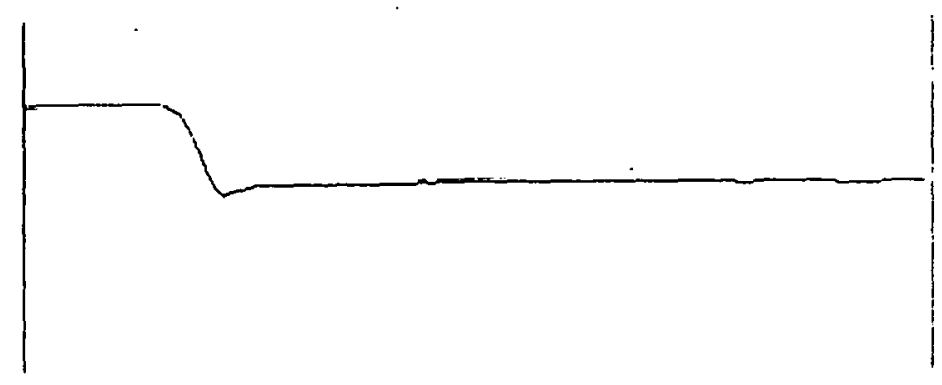

0.30
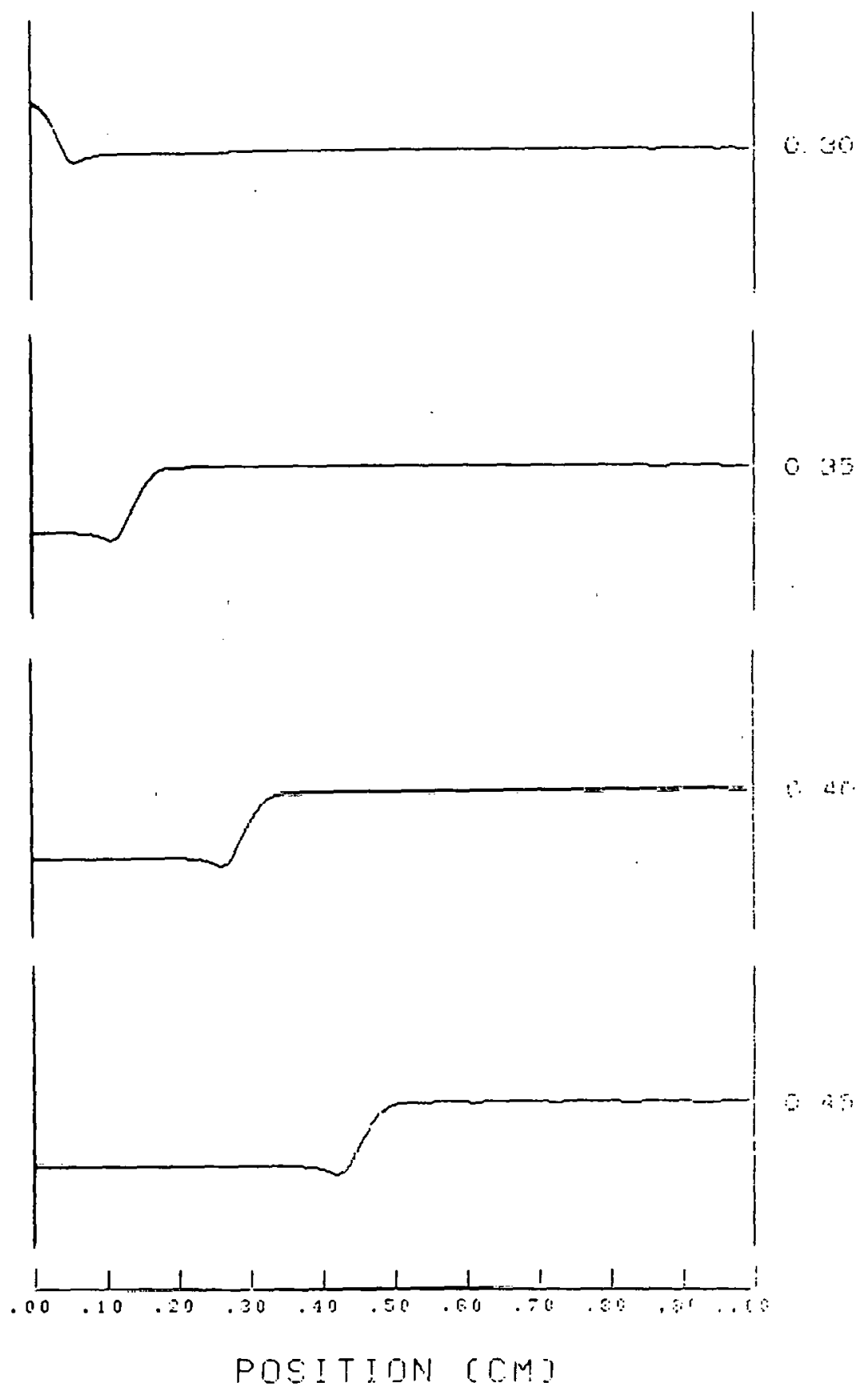

16 


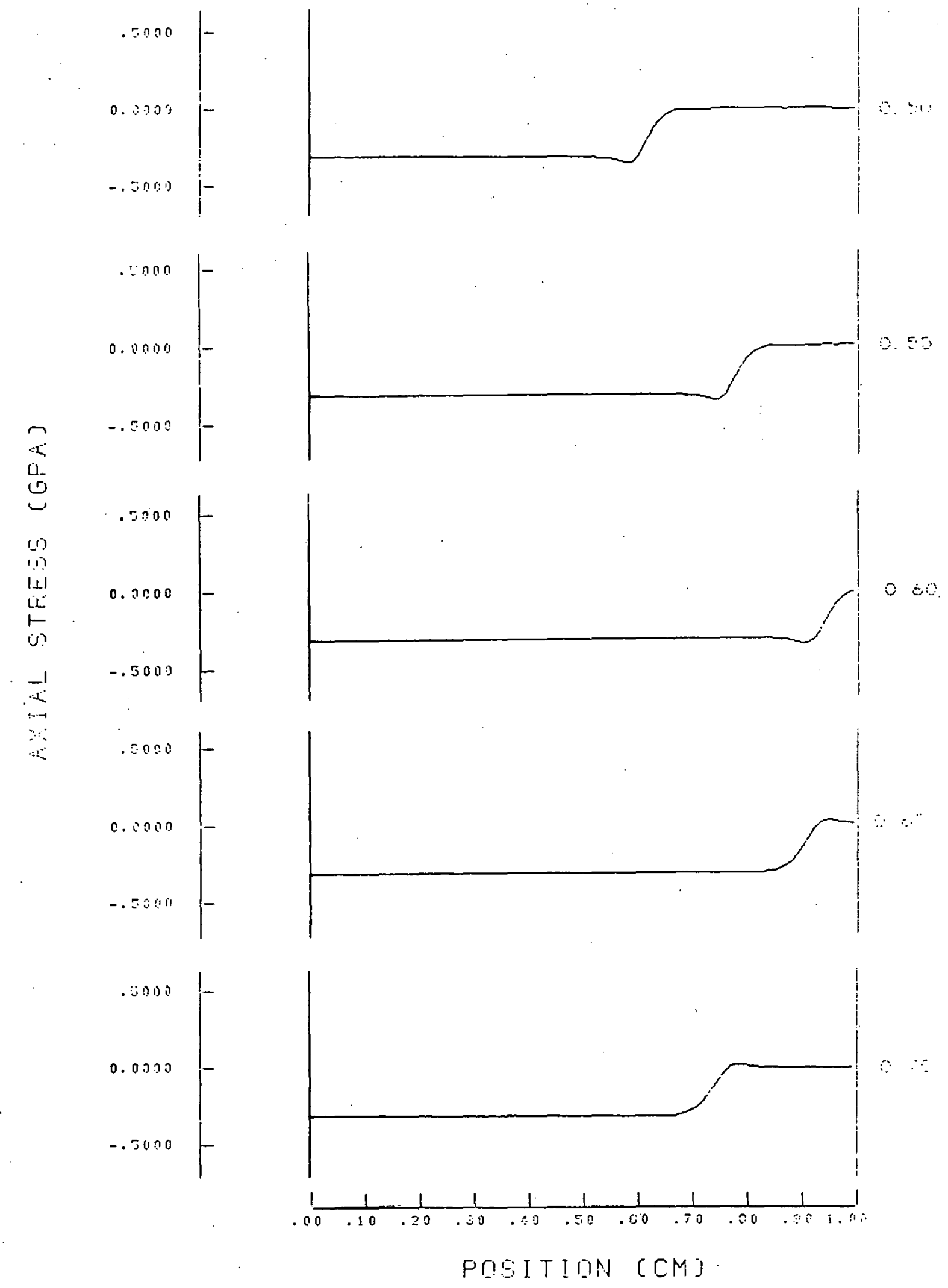




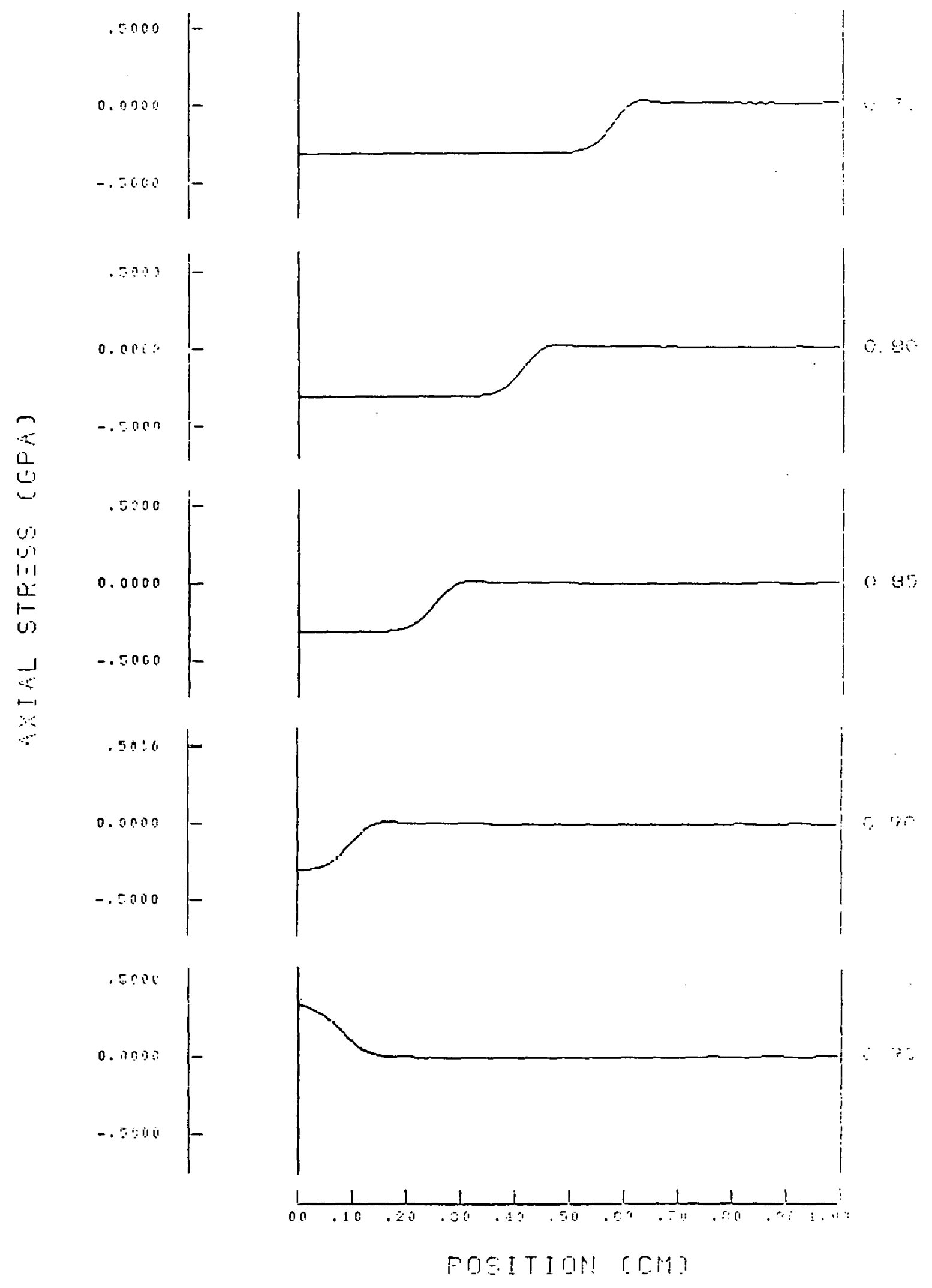



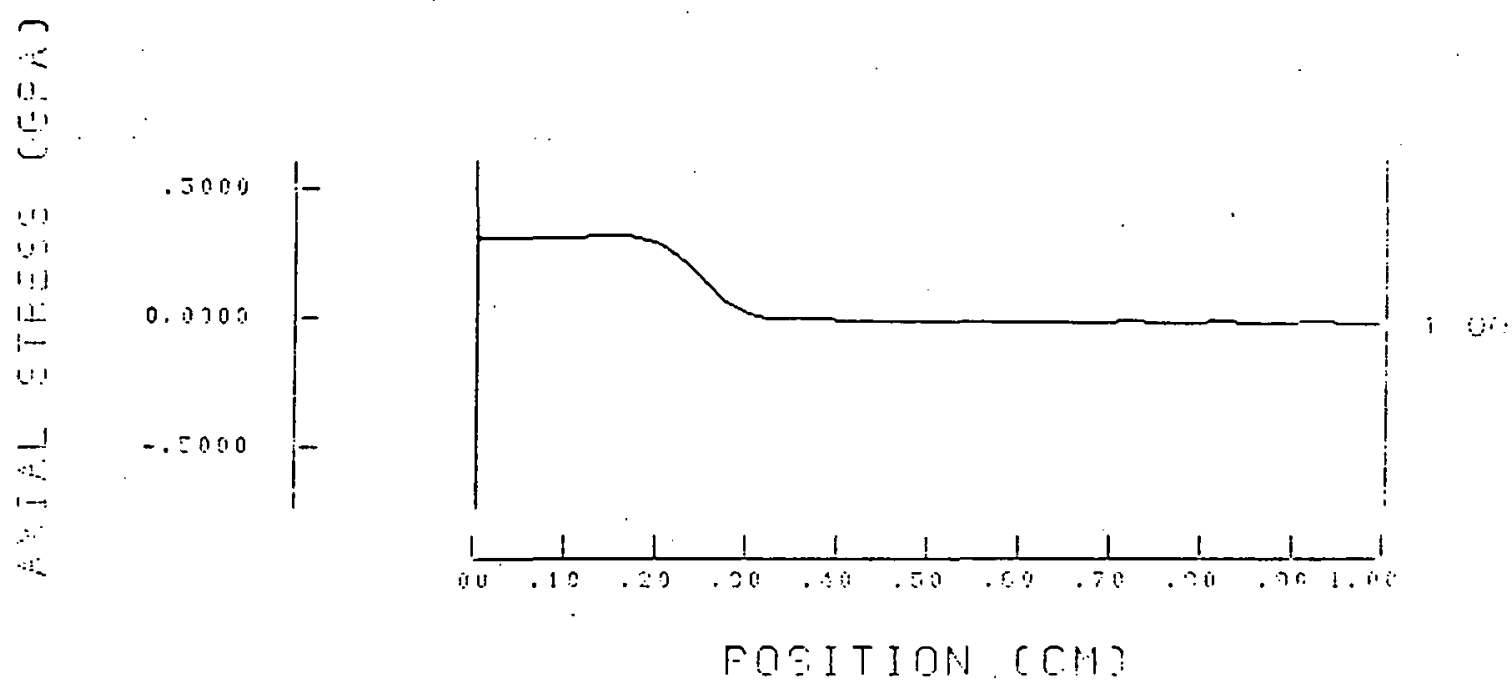

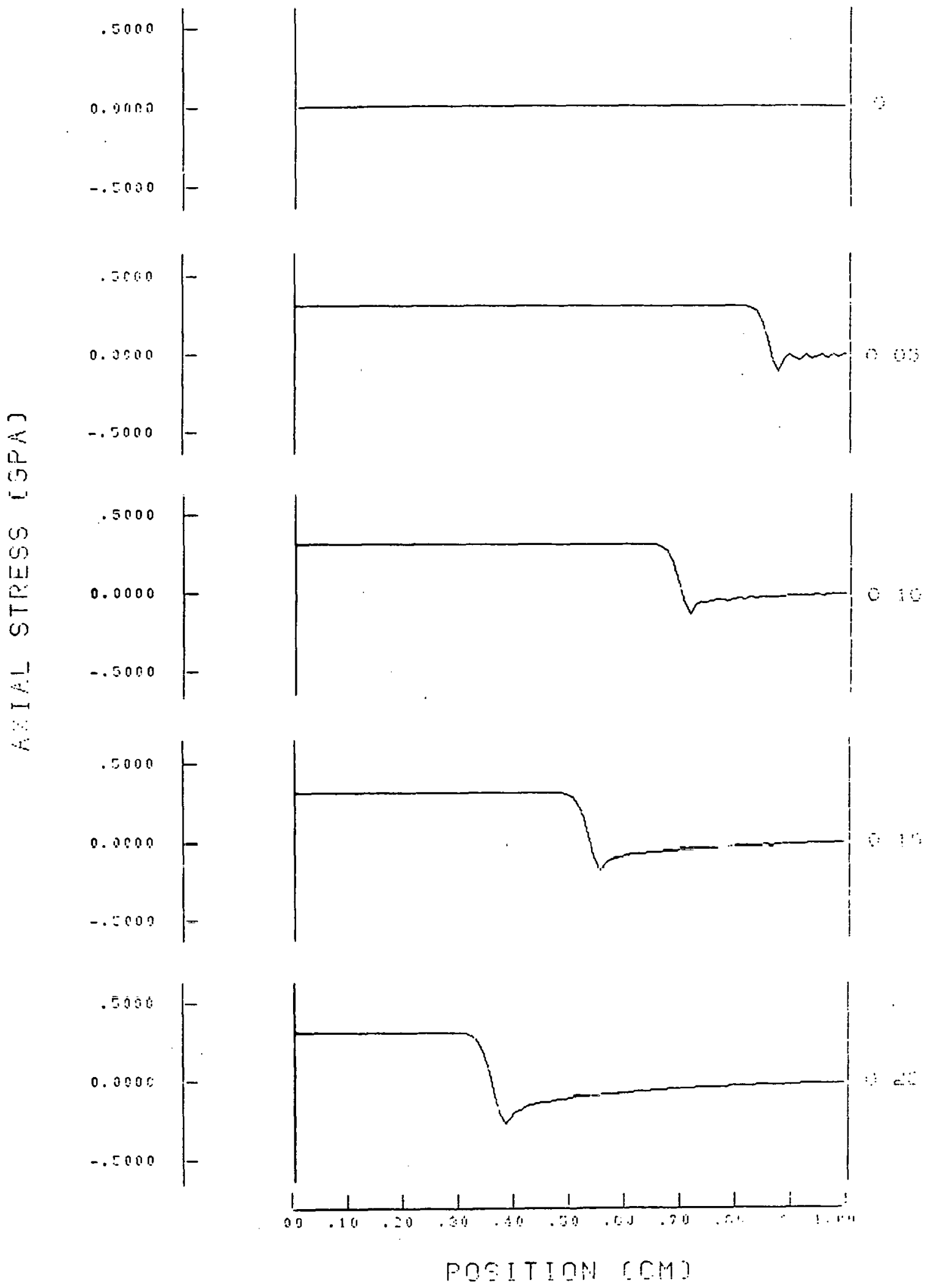


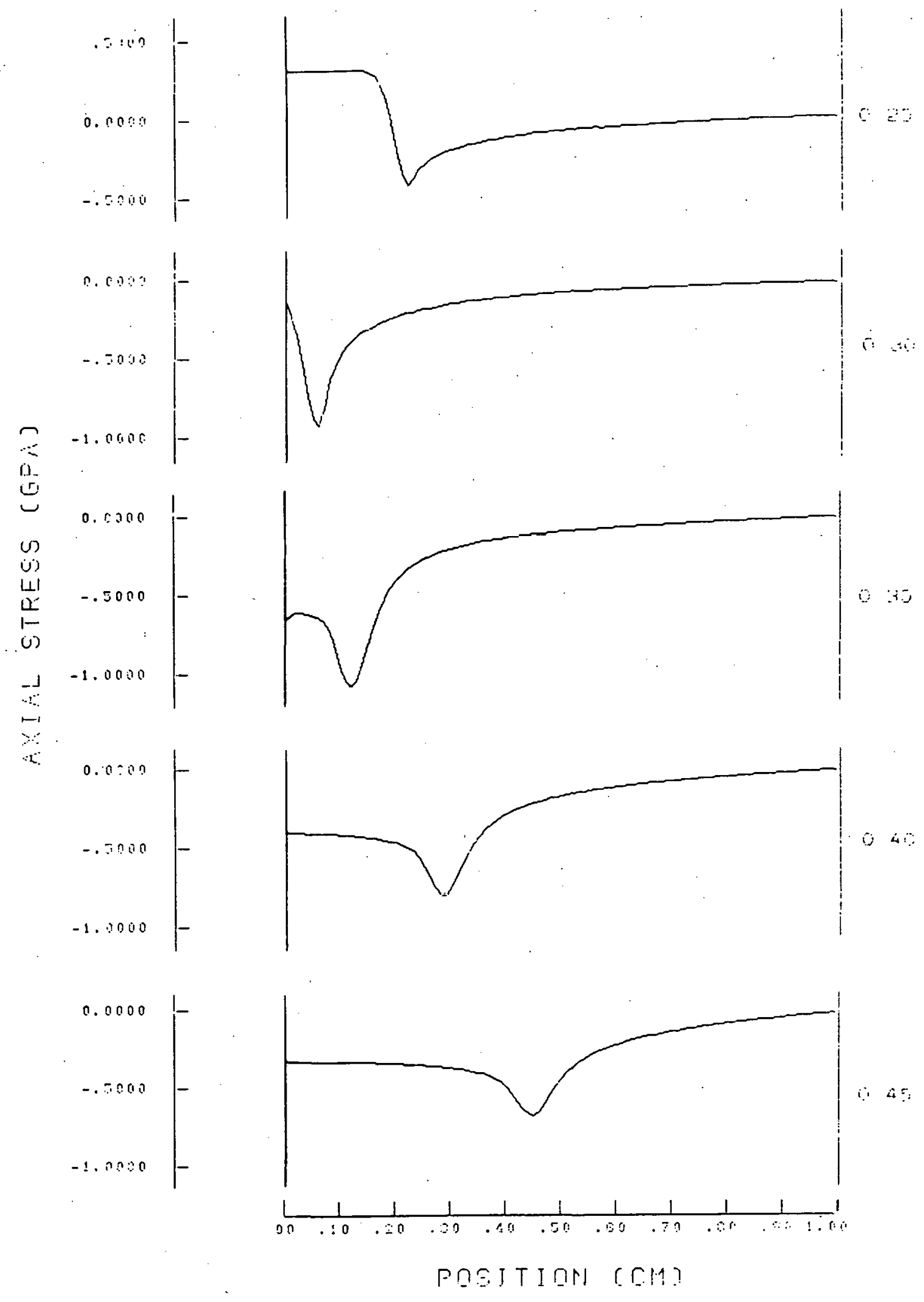




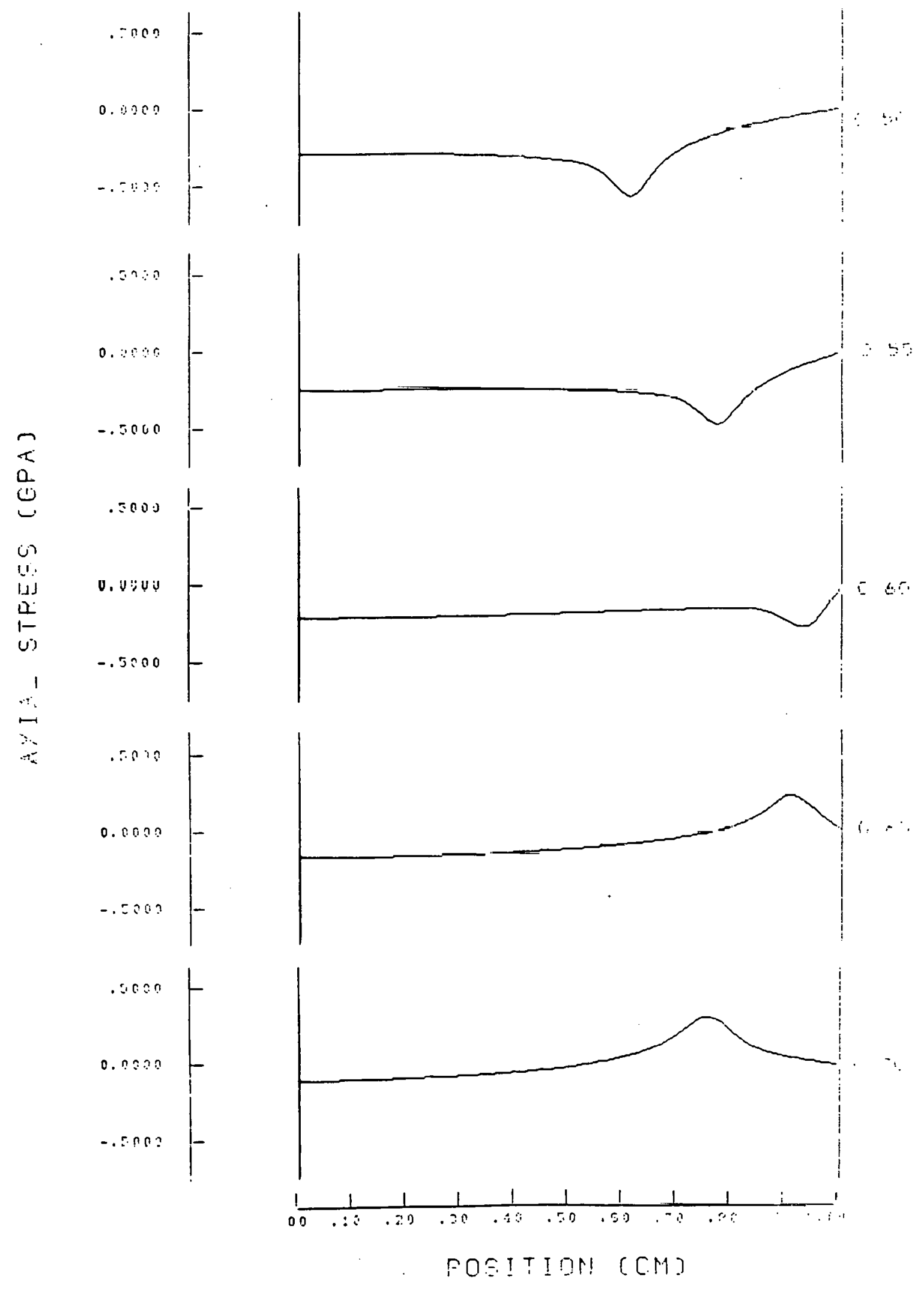




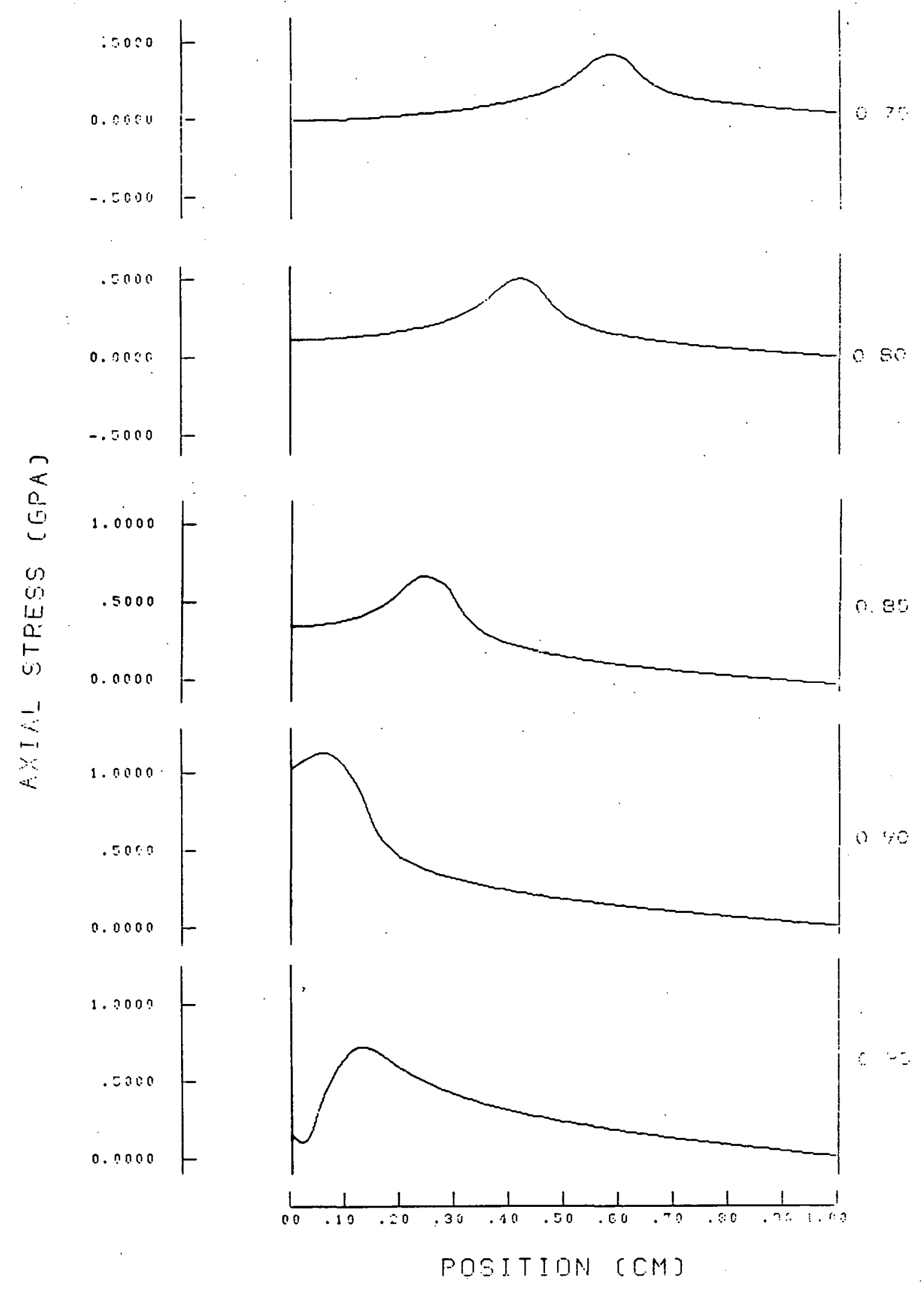



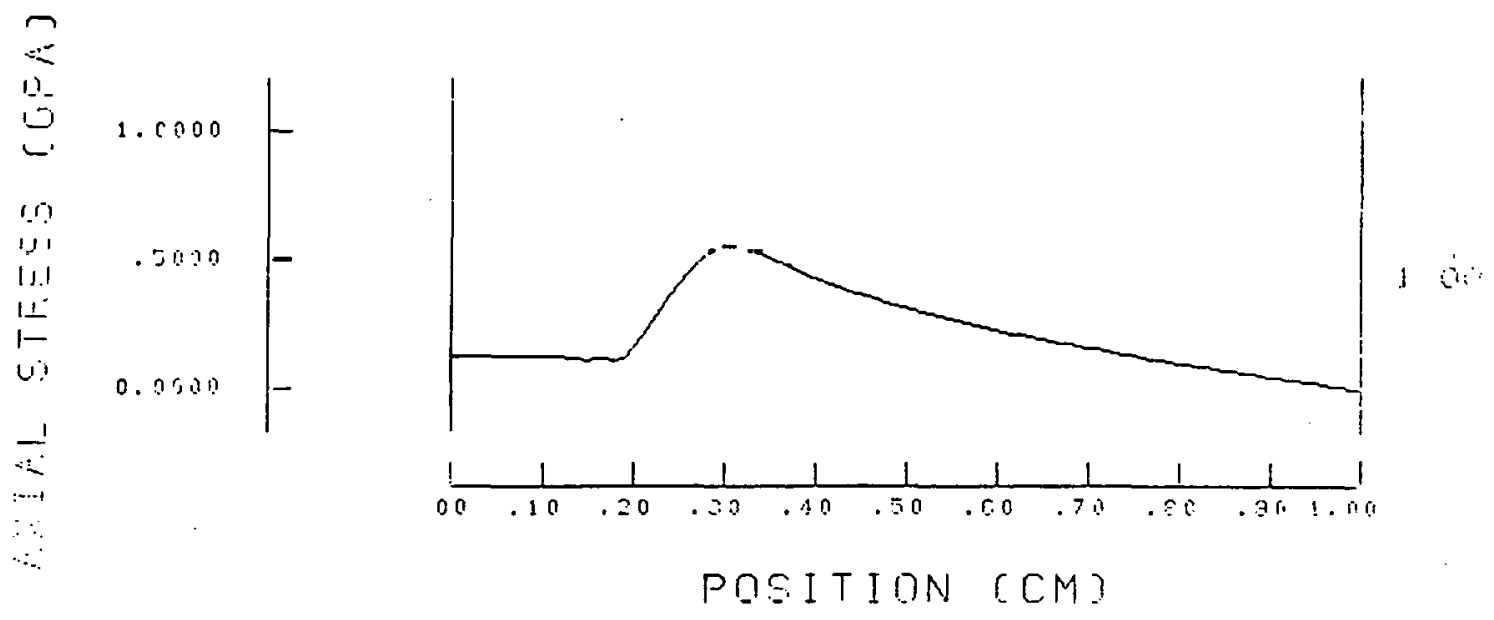
3. Solid Sphete -

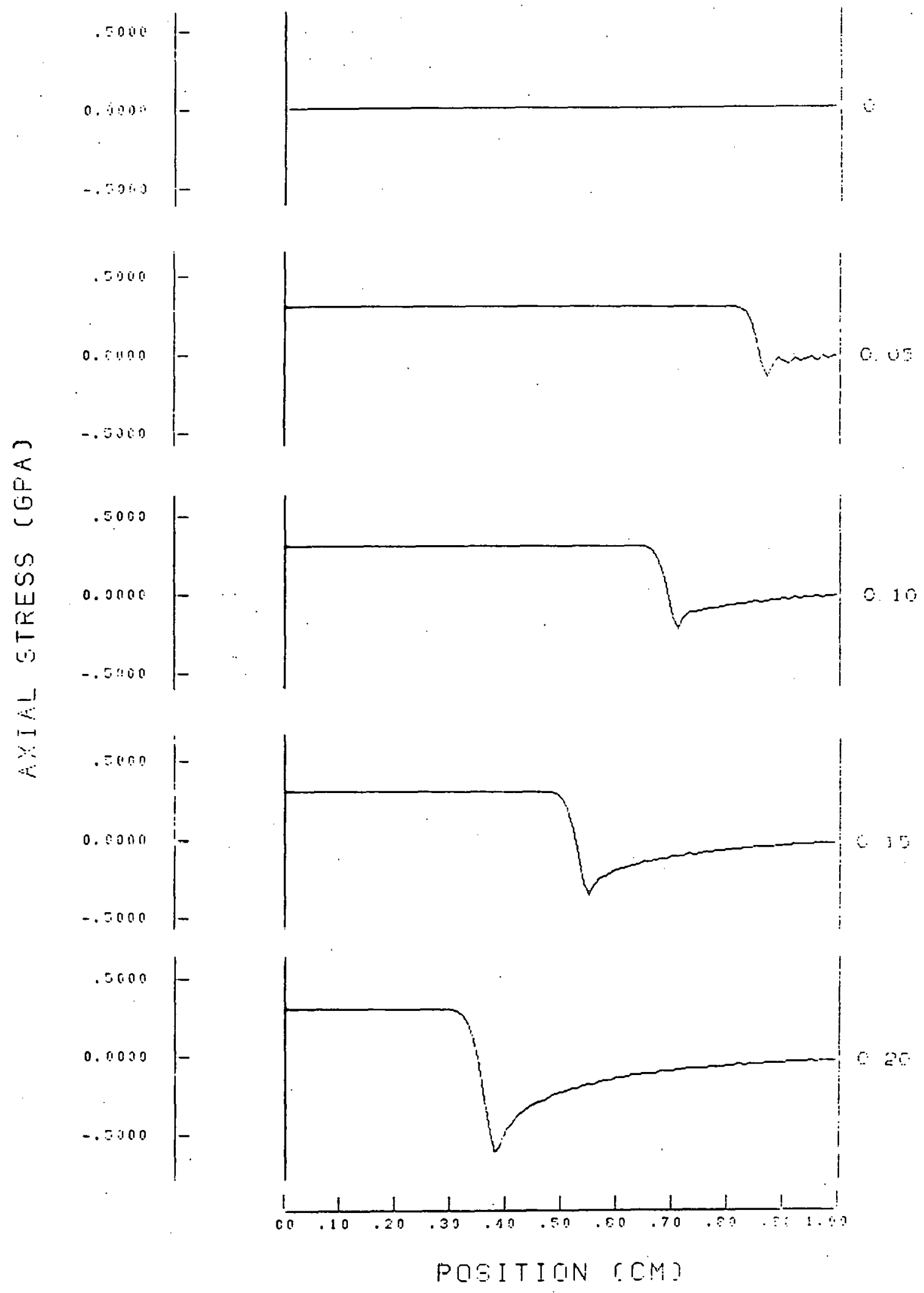




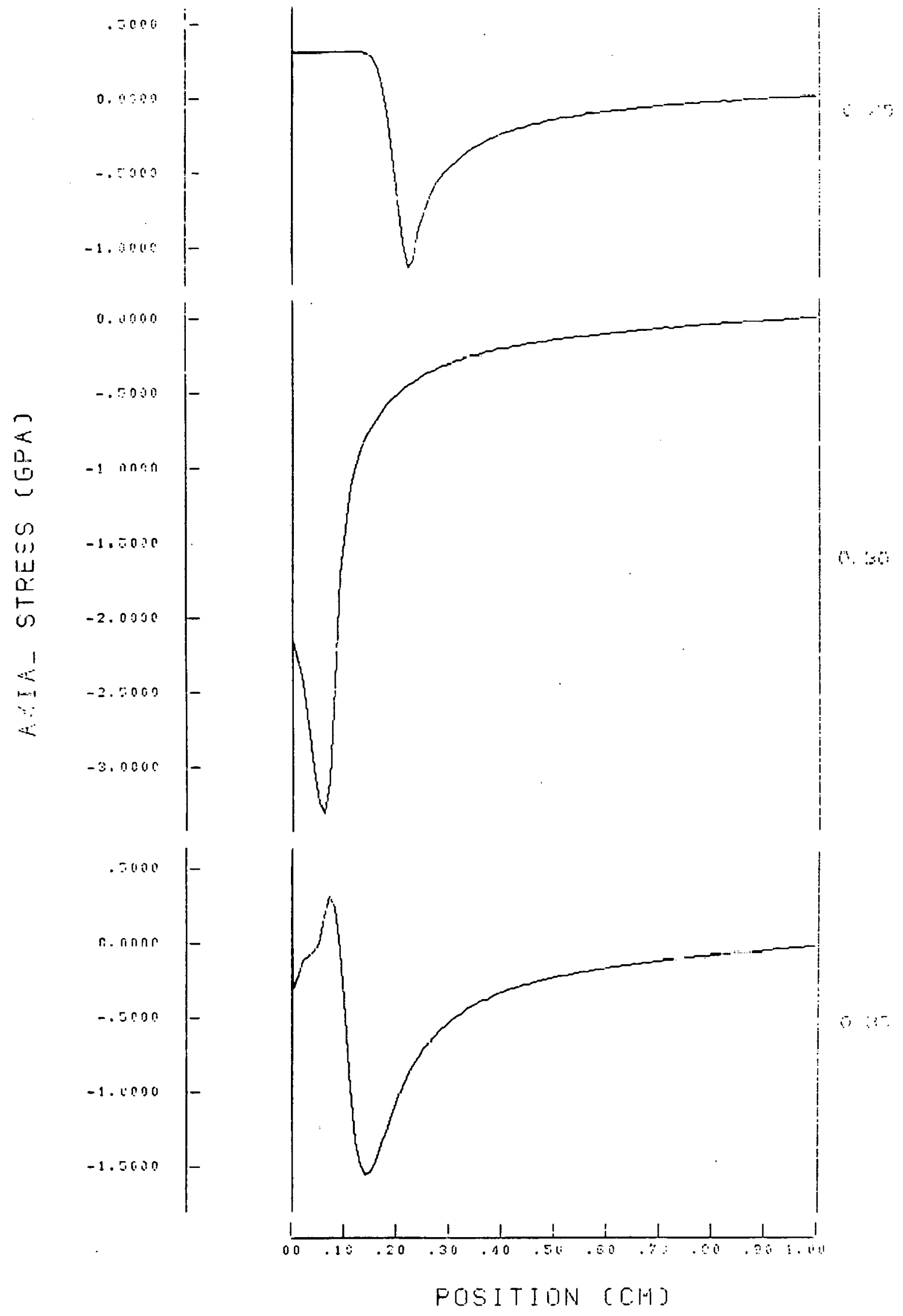




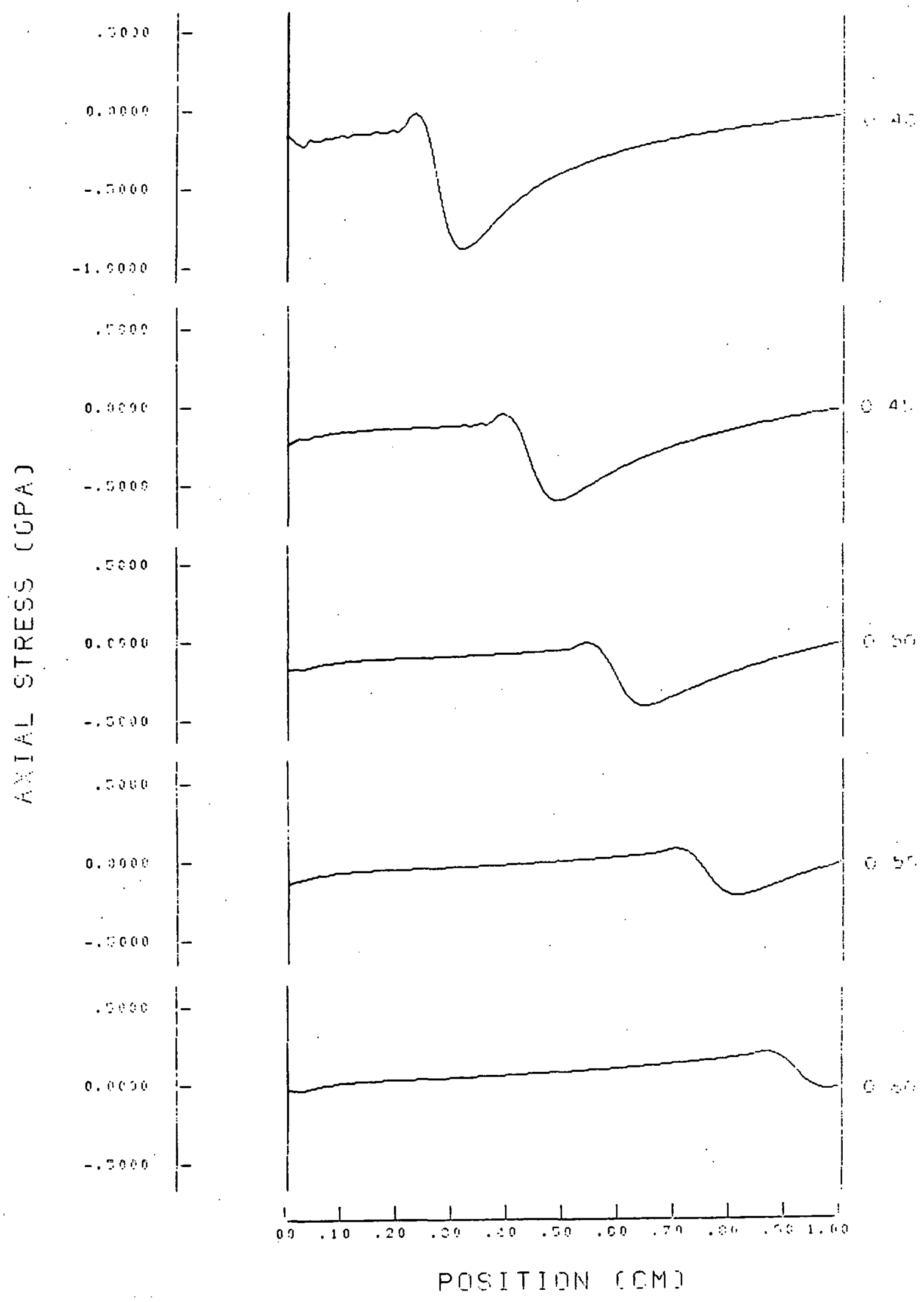




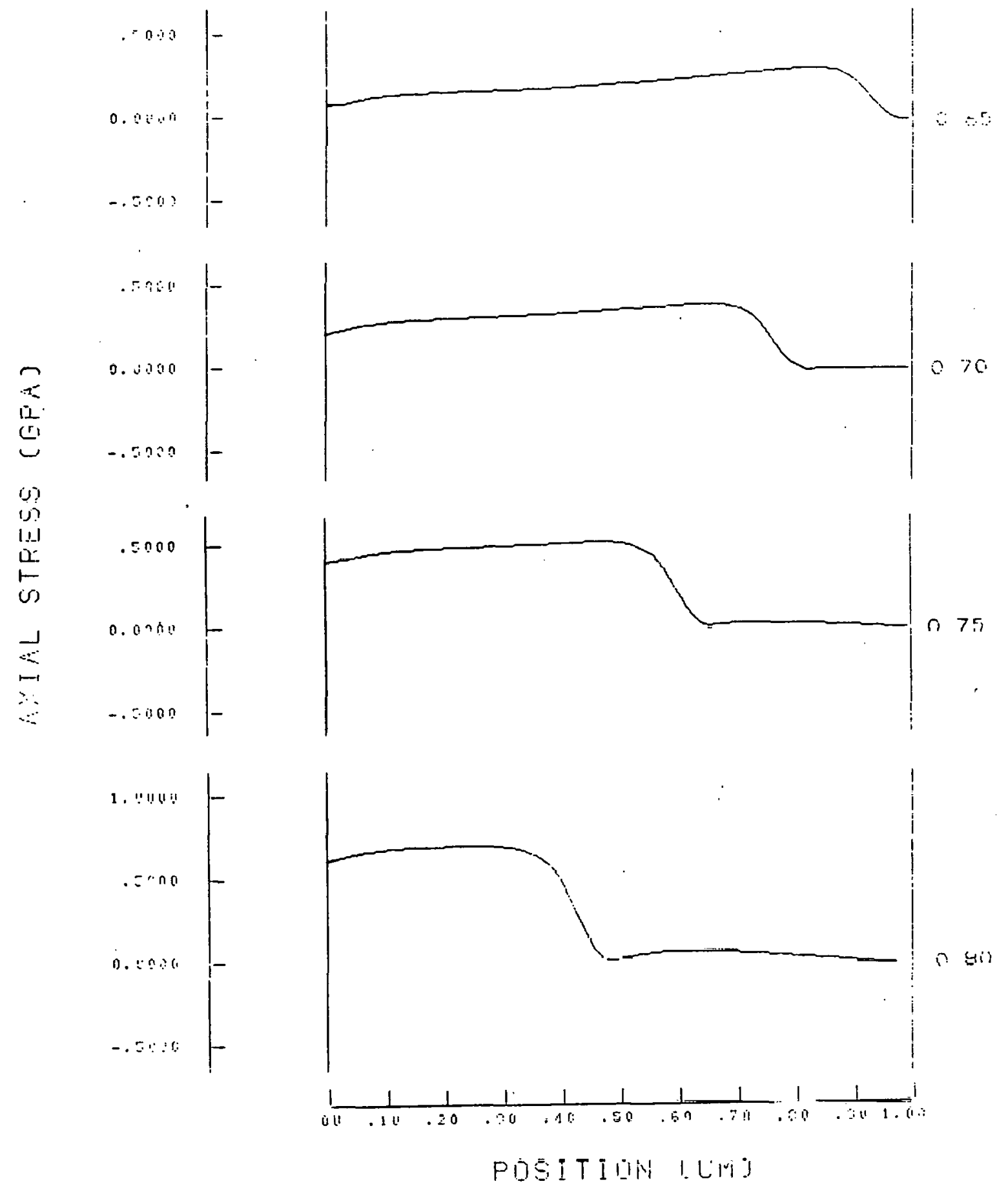




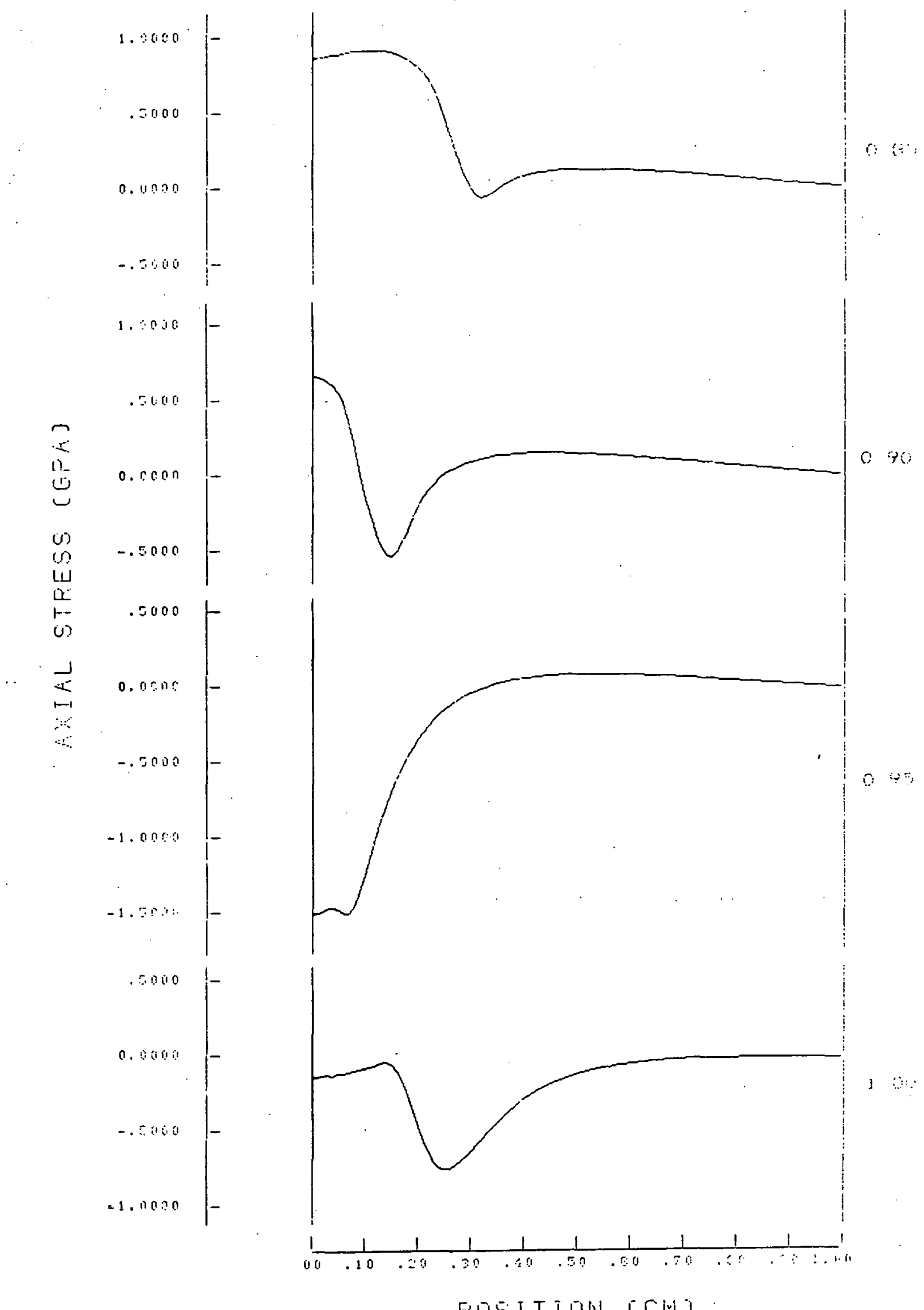

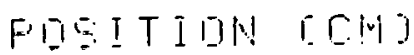


Distribution:

$\begin{array}{ll}4251 & \text { D. Cook } \\ 4452 & \text { J. Philbin } \\ 4452 & \text { J. Bryson } \\ 5500 & \text { O. E. Jones } \\ 5510 & \text { D. B. Hayes } \\ 5520 & \text { T. B. Lane } \\ 5530 & \text { W. Herrmann } \\ 5531 & \text { S. W. Key } \\ 5531 & \text { M. E. Kipp (15) } \\ 5533 & \text { A. J. Chabaj } \\ 8214 & \text { M. A. Pound (1) } \\ 3141 & \text { L. J. Erickson (5) } \\ 3151 & \text { W. L. Garner (3) } \\ & \quad \text { For DoE/TIC } \\ & \text { Unlimited Release } \\ 3154-4 & \text { C. Dalin (25) } \\ & \text { (For DOE/TIC) }\end{array}$




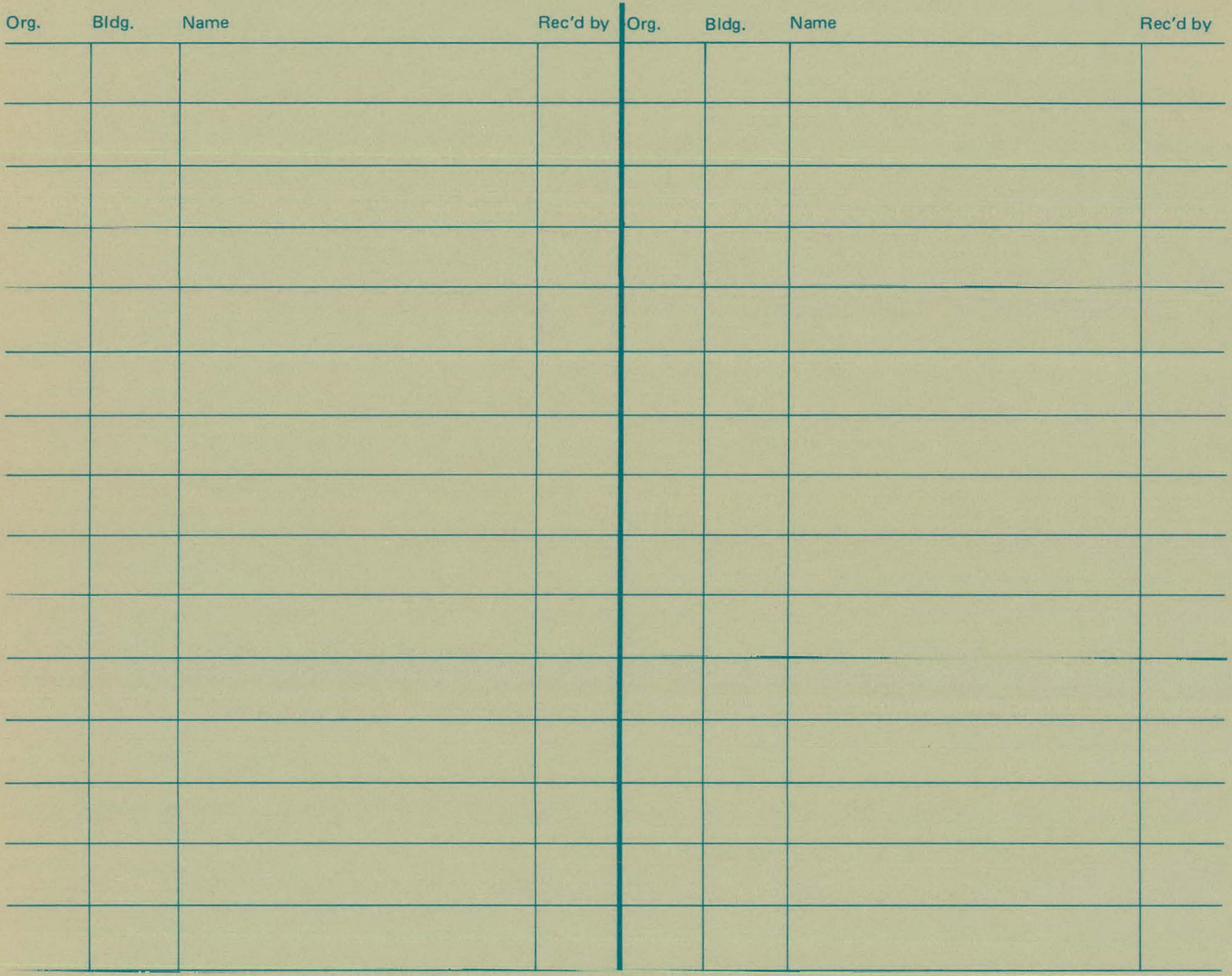

